\title{
In-transit distribution strategy: Hope for European factories?
}

\author{
Per Hilletofth $^{1 *}$, Frida Claesson ${ }^{1}$, and Olli-Pekka Hilmola ${ }^{2}$ \\ ${ }^{1}$ School of Technology and Society, University of Skövde, 54128 Skövde, Sweden \\ ${ }^{2}$ Lappeenranta University of Technology, Prikaatintie 9, 45100 Kouvola, Finland
}

\begin{abstract}
In this research the in-transit distribution strategy is investigated by determining and analyzing key principles of the strategy. It is examined through a multiple case study and simulation. This research reveals that the in-transit distribution strategy is about considering goods that are being transported as a mobile inventory and actively dispatching goods to a destination, where there is a predicted demand before any customer orders are received. It can give major competitive advantages by offering rather short lead-times for customers without having to store products locally. This, in turn, gives lower warehousing costs, lower tied-up capital, a less interrupted manufacturing, and steady as well as continuous production volumes. It is a workable solution for European manufactures competing in distant market. To be successful with this strategy, it takes good planning, working closely with customers, first-class market knowledge, and a supporting enterprise resource planning (ERP) system. Other highlighted requirements are low variation in demand and predictable distribution lead-time. Simulation study of one hypothetical product group verified case study findings, but we find it interesting that especially manufacturing output variance is very sensitive regarding to the overall results. Also increasing average customer demand results in undesired outcomes.
\end{abstract}

\section{Introduction}

Nowadays most supply chains are international, which means that raw material and products are procured from all over the world, transformed into new products in specific regions and then sold on a global market [1]. From a logistics point of view, globalization started with the use of so-called focused factories. The idea behind focused factories is that each factory produces only a limited range of

* Corresponding author: Tel.: +46 (0)500 4485 88; Fax: +46 (0)500 4487 99; E-mail: per.hilletofth@his.se 
products for the whole global market [2]. Lately, the globalization has also led to increased competition, which can be deduced by increased product ranges, shorter product life cycles and increased customization [3]. Since suppliers still want to achieve economies of scale in production by the use of focused factories, and customers at the same time demand custom-made products and shorter lead-times, distribution becomes a key factor in order to become successful [4-6]. Distribution is executed through transportation process, which has been under interest in global manufacturing research lately, e.g., ever larger manufacturing companies, transportation delays, accuracy and new emerging market opportunities [7-11].

In the logistics literature there are traditionally two main strategies for distributing products to the market: The centralized distribution strategy and the decentralized distribution strategy [12-13]. The advantage by using the centralized distribution strategy is that it usually leads to a higher service level at a lower cost; the disadvantage is that customers may have to wait longer for their products [14]. The decentralized distribution strategy often leads to shorter lead-times and a higher flexibility, the disadvantage being that products may have to be stored at several places, which generate higher warehousing costs [14].

Depending on how many central warehouses there are in the global distribution system a change into distribution via local warehouses to central warehouses might have a considerable effect on the lead-time, but could still be interesting from a cost and tied-up capital point of view. In markets where the customer is used to and might also be demanding short lead-times there could often become conflicts. When these conflicts occur it would be advantageous to have an alternative to the two main strategies that combines their advantages, i.e. an alternative that creates shorter lead-times than the centralized distribution strategy and gives lower costs and tied-up capital than the decentralized distribution strategy. In recent times the question has arise about whether or not the in-transit distribution strategy might be exactly this alternative.

The in-transit distribution strategy means that products or goods that are being transported are seen as mobile inventory and companies work actively with dispatching goods to a destination where they predict a demand before any customer order is received [15]. There are many complications with the in-transit distribution strategy that companies have to handle in order to become successful. One of these complications that have to be considered is if there is no customer order before the goods reaches its destination. The supplier must have a plan for how to store the goods after it has reached its destination but while waiting for a customer order. It is also important that the costs for this intermediate storing are not too high and the handling not too complex. Another important aspect to consider is whether or not the ERP system or information system used is sufficient enough to support the strategy. Among other things the difficulty is to keep track of the goods and the quantities at the different locations, this complicates the calculation of a correct delivery date to the customer.

The purpose of this research is to describe the in-transit distribution strategy by determining and analyzing key principles of the strategy as well as by illustrating its application in practice. The specific research questions are: (1) 'What kinds of advantages can the in-transit distribution strategy provide?', (2) 'When is the intransit distribution strategy appropriate to use?', and (3) 'Can the in-transit 
distribution strategy be used as a complement in centralized/decentralized distribution structures?'. The applied research strategy has been a multiple case study and simulation approach, which corresponds well with the explorative and descriptive purpose of this research. Both the case companies (to remain anonymity here called Alfa and Beta) are Swedish manufacturers that act on a global market within the chemical industry. Empirical data has been collected from various sources to enhance understanding by examining the research object from several perspectives. Firstly, this study is based on data gained from in-depth interviews with persons representing senior and middle managers in the case companies; logistics manager, transportation manager, and IT manager. The interviews have been conducted based on the same interview structure during 2009. A system dynamics simulation model concerning the use of in-transit distribution strategy in one product, one factory and one major market setting has been developed and analyzed to further verify case study findings.

\section{In-transit distribution strategy}

There is not a single distribution solution for all kinds of products, manufacturing units, markets, and acting companies 10]. It is important for companies to map out the needed prerequisites and thereafter chose a suitable strategy. How the traditional strategies, the centralized and the decentralized distribution strategy, work is already described in existing literature [13], as well as questions regarding why and when to use them [14]. One area that is not thoroughly described in the literature is how these traditional issues relate to the in-transit distribution strategy, and there are not many research papers done regarding the area of the in-transit distribution strategy.

The in-transit distribution strategy means that products or goods that are being transported are seen as mobile inventory and suppliers work actively with dispatching goods to a destination where they predict a demand before any customer order is received [15]. The supplier should transport the goods to a destination close to where the expected demand will arise in order to quickly be able to send it to the customer. When choosing destination it is important to take into consideration where the goods may be stored intermediately if the supplier has not received a customer order before the goods reaches its destination.

Due to the fact that the purpose of the in-transit distribution strategy is that goods are being dispatched before a customer order is received, and is based on an expected demand, the flow of goods is planned exclusively by forecasts. Hence, an efficient forecasting is essential in order to succeed using this strategy. To be able to distribute the goods to the customer in a cost-efficient way the supplier has to avoid intermediate storing and the need of this is determined by how well the forecasts correspond to reality.

How to deal with the uncertainty in demand is traditionally based upon using a safety stock, which is calculated by using normal deviation between forecast and actual outcome [14]. This mode of procedure does not work for the in-transit 
distribution strategy; consequently the uncertainty has to be dealt with differently. Since the goods is already shipped when a negative deviation is observed the supplier must have been foresighted and included a safety quantity in the delivery in order to compensate for the deviation. In the in-transit distribution strategy even positive deviations are severe when creating a need for intermediate storing. This means that safety quantities can cause troubles for suppliers and they have to find a proper balance between customer satisfaction and intermediate storing. As goods when utilizing the in-transit distribution is typically supplied from a distant location, the demand in the market place should be stable with respect to quantity and regularity [10].

The in-transit distribution strategy could offer a shorter lead-time than the centralized strategy and lower warehousing costs and tied-up capital than the decentralized strategy and this is why it should be able to be complementary to certain types of products, customers and markets. In order to put the in-transit distribution strategy into practice in a capable way it is crucial to have an efficient information system able to tell where the goods is, where it is going, and when it will reach its destination. Any company using the in-transit distribution strategy has to be aware of that it is considerably harder to keep track of where the goods is when using a global distribution system. This reasoning follows the present research in distribution which emphasize that information systems have become a key factor for success. Another disadvantage with the in-transit distribution strategy is that it requires a good forecasting, good cooperation in the supply chain and a substantial knowledge about the market in order to achieve time- and place utility. If these demands are not fulfilled there is a major risk of the goods being transported unnecessary long distances and that it is located on markets where there at the time exist no demands for it [16].

There are already models developed to aid when choosing distribution strategy. However, these models only deal with the centralized and the decentralized strategy. Harrison and van Hoek [17] have developed a model, which base its choice by three factors: (1) Short or long lead-time, (2) Low or high deviation in demand, and (3) Focus on distribution costs or focus on warehousing costs. These parameters are chosen because they have a great impact on the distribution. Since the in-transit distribution strategy is a kind of a hybrid of the centralized and the decentralized strategy it has been included in the model in Fig. 1.

The in-transit distribution strategy is placed where the customers demand relatively short lead-time and where the demand is stable. The strategy is not able to offer a very short lead-time in a cost efficient way when there is a high deviation in demand, than there is a risk of having a lot of intermediately stored goods while at the same time multiple scarcities might occur. The strategy has not been placed as a replacement but as a complement. In order to emphasize this, the in-transit distribution strategy has been placed in the figure with dotted lines.

The purpose of the elaborated model is to help companies find the distribution strategy, or the combination of strategies, that best can take a company's preconditions for specific products, customers, or markets into consideration. However, it is only a support for decision and the company might have to include other decision variables when choosing distribution strategy. 


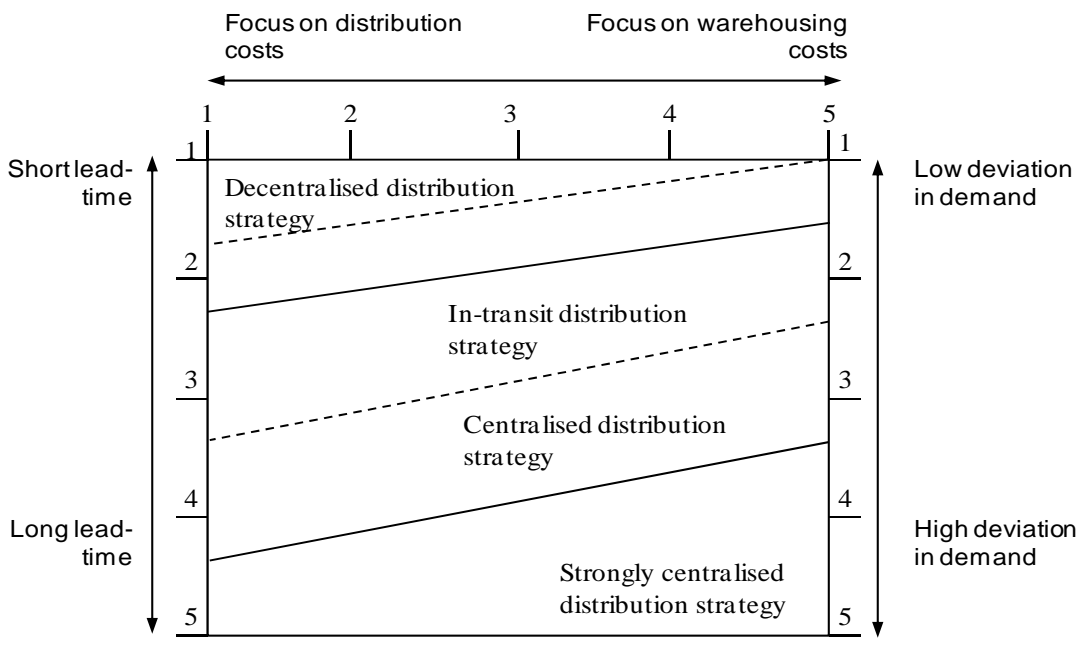

Fig. 1. The choice of distribution strategy (adapted from [17])

In order to make the model more useful every parameter has been graded with a one-to-five scale. This has been done in order to facilitate companies' choices by helping them make a table of their customer segments and product groups where they estimate the value of each parameter. When utilizing this model a table should be created, which shows how the company estimates the different parameters per customer segment and product group. This is made with the starting point of what the customers demand and what the company prioritizes.

\section{Case study findings}

\subsection{European manufacturer Alpha}

Alfa is a multinational company that has built a global distribution system by the use of focused factories, central warehouses, and local warehouses. Primarily they use the centralized and the decentralized distribution strategy to supply their customers with products. Lately however, they have also been starting to use the in-transit distribution strategy to a limited extent.

The in-transit distribution strategy is today used in People's Republic of China, in this paper referred to as China, as a complement to the traditional methods. It is primarily used for large customers with a stable demand and for high volume products. The aim of using the strategy is to be able to offer the customers short delivery times without having to store large volumes of goods locally. The intransit distribution strategy is also used from a sales point of view, which means that the sellers in China, thanks to this strategy, are able to negotiate on the price at a much later time. It also means that they can offer prices that are adjusted to 
conditions on the market as close to the delivery date as possible. This is a crucial success factor on the sellers' markets consisting of many competitors and where the customers mostly focus on cutting prices.

The in-transit distribution strategy works in a manner that a plan for the expected demand is completed by using forecasts. The plan extends over three years and has a period length of a month. The forecasts and the plan are updated four times per year when the sellers make contact with the customers in order to see what the expected demand will be for the coming months. The plan contains information on which products to send, how much to send, which destination the products have, and when in time they should reach their destination.

To guard against uncertainty in demand, Alfa sends a larger quantity than the expected demand. This they can do due to the fact that it is relatively easy to store the products that are not sold during the transport. The destinations are in this case ports and the company tries to choose ports that are as close to the predicted demand as possible as well as ports that have closeness to local warehouses. When, in time, the goods is supposed to reach its destination port is calculated to be as close as possible to when in time the expected demand will occur.

Alfa sees the administration costs for the in-transit distribution strategy as a crucial area. The turnaround time is one hour more per order for the in-transit distribution strategy compared to an order that is for the centralized distribution strategy. This extra hour is a direct consequence of an insufficient information system that leads to a lot of unnecessary manual work.

\subsection{European manufacturer Beta}

Beta is a multinational company that has built a global distribution system by the use of 40 production plants in combination with both central and local warehouses. They are primarily using the centralized and the decentralized distribution strategy to supply their customers with products. However, lately they have, just like Alfa, started to use the in-transit distribution strategy, but within limited extent.

The in-transit distribution strategy is today used primarily for two customers in the United Kingdom (UK) instead of the traditional approach. These two customers are buying large volumes of standard products. The purpose of using this strategy is to be able to offer the customers the same delivery times as when production and the warehouses would be located in the UK. Another reason was that it was difficult to keep the promised delivery times, when using intermodal transports. The in-transit distribution strategy then became a way of reducing the risks and keep delivery times.

The in-transit distribution strategy is based on a forecast for which quantities to distribute, made customer per customer. The forecasts are for one year ahead and are being modified four times-a-year. The critical factor for when an order is placed is the customers historical order pattern in combination with the experience of the person placing the order. This person also has a continuous contact with the sales person in the UK to get information of the customers' changed demand. The person placing orders decides on how long before predicted demand an order is 
supposed to be in port, but it is the carrier that decides which port to use. Since the demand varies Beta needs to guard against uncertainty, which they do by always ordering a certain amount more than needed. This is made possible by being able to easily store the goods in the port.

Beta sees the administration costs for the in-transit distribution strategy as a crucial area due to the fact that most of the administration is handled manually by one person as there is a considerable lack of a sufficient information system. By not having a sufficient information system Beta cannot follow up on how long the goods is stored in the port.

\section{Simulation findings}

A system dynamics simulation model from the use of in-transit distribution strategy in one product, one factory and one major market setting has been developed to further verify case study findings (Fig. 2). In the model production is driven (left side of Fig. 2) by the end item inventory amounts, and when inventory position is below certain amount, production is allowed to produce (modeled with feedback relation).

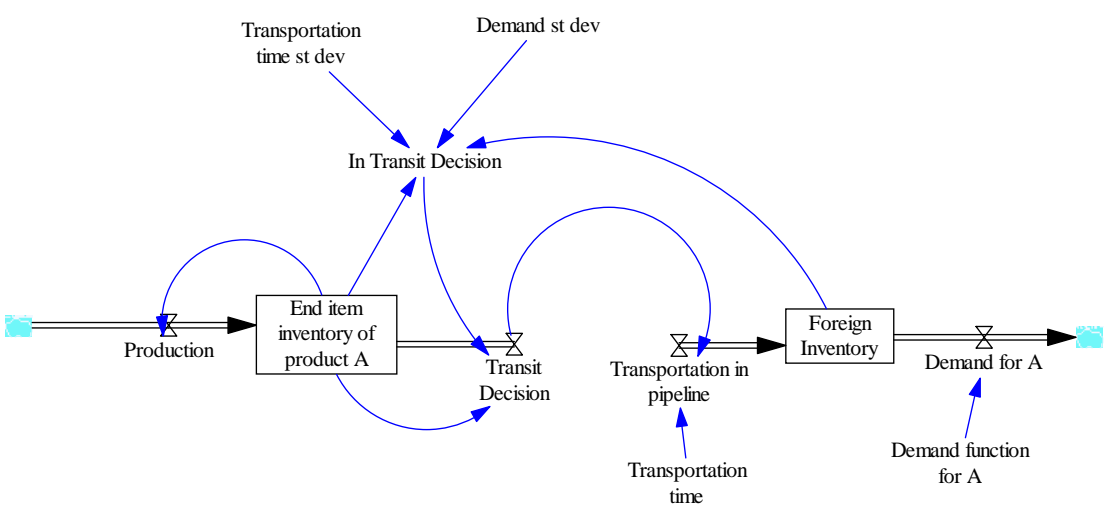

Fig. 2. System dynamics simulation model for in-transit distribution strategy of one product to be supplied from one distant factory to one main market place.

Release of produced end item inventory is followed by parameter "in-transit decision”; as end item inventory (production) reaches needed level (e.g., 400 units), "in-transit decision" (in the middle upper part of Fig. 2) checks with reorder point calculations from "foreign inventory" (takes into account standard deviation of demand and transportation lead-time variation), if more products should be send over for distant market. Decision of sending products is based on the assumption of transportation lead-time variation as well as demand variation. These do not have connection on real demand generated by the model. After 
authoring production end-item inventory to send products for long-distance market, model contains time delay in overall transportation operation. In case of Asian markets reached from Northern Europe, this delay is typically from 6-7 weeks up to 14. After this transportation process production lot (approx. 400 units, depends from the situation and needs) arrives into foreign inventory destination from where products are distributed for customers based on demand. However, as demand has always uncertainty, then inventory holding is inevitable although tried to be minimized with smart "in-transit decision".

Even if there exist two main variance sources in the model (end demand and transportation time), it is rather easy to select parameter values (e.g., production rate) and incorporation of two aspects of uncertainty in reorder point, the performance becomes predictable. Fig. 3 illustrates this situation, where foreign inventory has variation, but all of the customer demand is being met, and within 75 percent likelihood inventory holding (and needed space) is predictable. Monte Carlo simulation feature enables to have such uncertainty modeled and tested in the system dynamics simulation model. However, possible caveats of in-transit distribution strategy are located in the low variation in production amounts of home country as well as in the balance of production versus demand. Fig. 4 illustrates situation, when weekly production capacity is a bit higher than in base situation (average is 37 units per week), but contains some small amount of uncertainty.

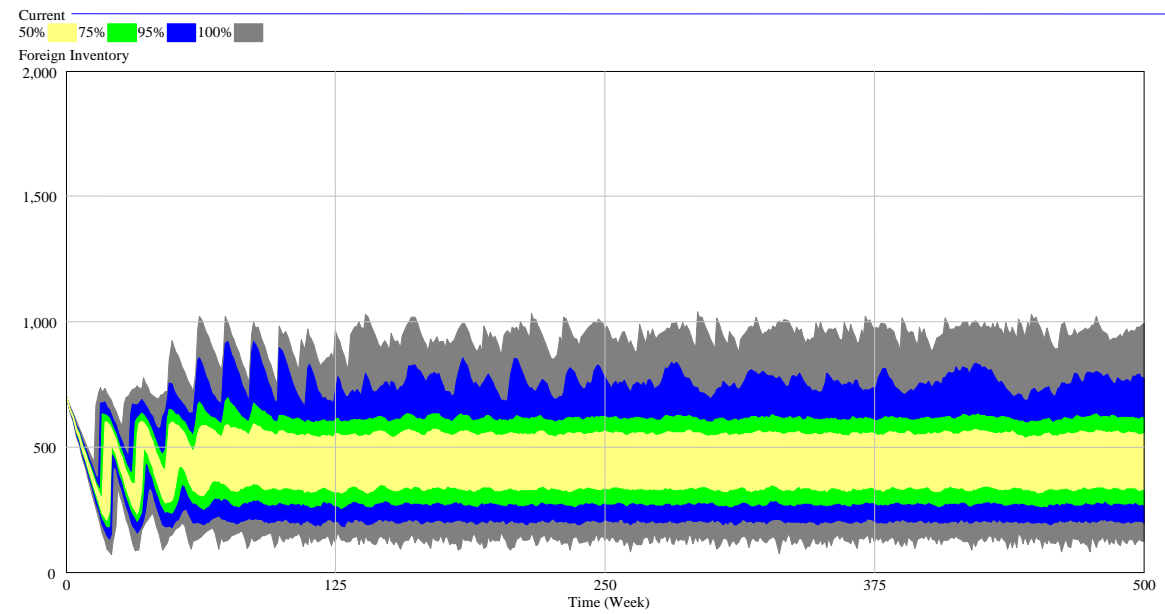

Fig.3. Inventory amounts in foreign inventory as production is stable (35 units per week), but holding somewhat larger capacity per week as end demand (Random Uniform, Min. 20, Max. 40, Mean 26.5 and st. dev. 2), and transportation process having uncertainty in its delay (Random Normal, Min. 7, Max. 14, Mean 11 and st. dev. 2).

In longer period of time, in-transit distribution strategy may encounter supply problems. These problems are only fostered further, if average demand increases a bit, and production contains still earlier mentioned variation (Fig.5). Of course on the average performance is good in these situations, but for supply organization 
having aims of high customer service and delivery accuracy, the magnitude of uncertainty in deliveries might be too much (especially in case of Fig. 5, but also Fig.4).

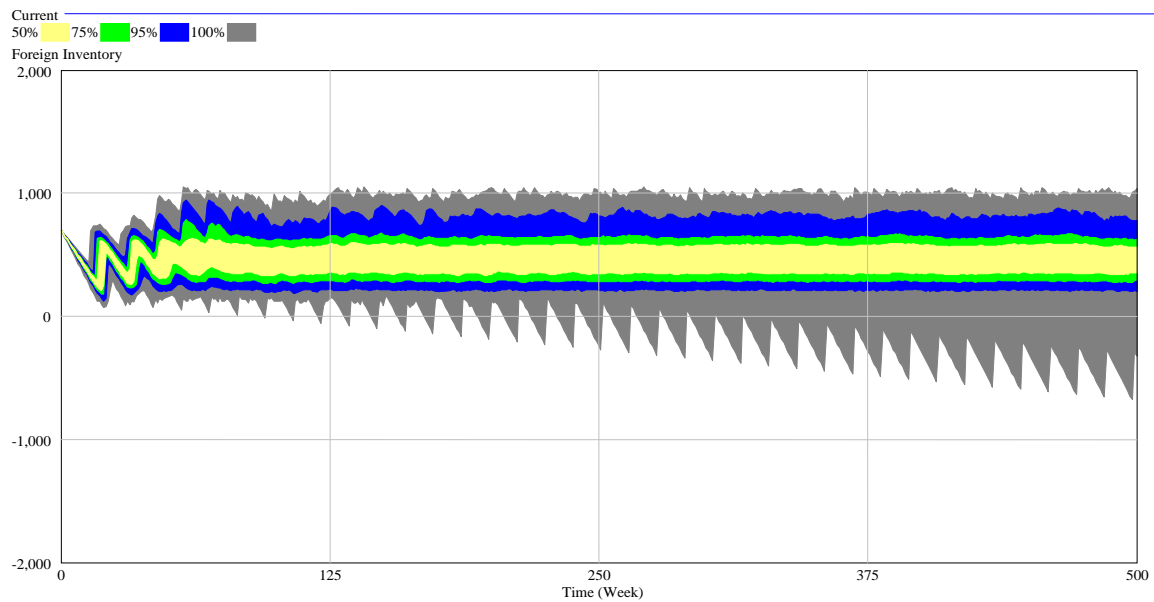

Fig. 4. Inventory amounts in foreign inventory as production is having low variation (uniform distribution 35 to 39 units per week), but still holding somewhat larger capacity per week as uncertain end demand (same as before), and having uncertainty in the delay of transportation process (same as before).

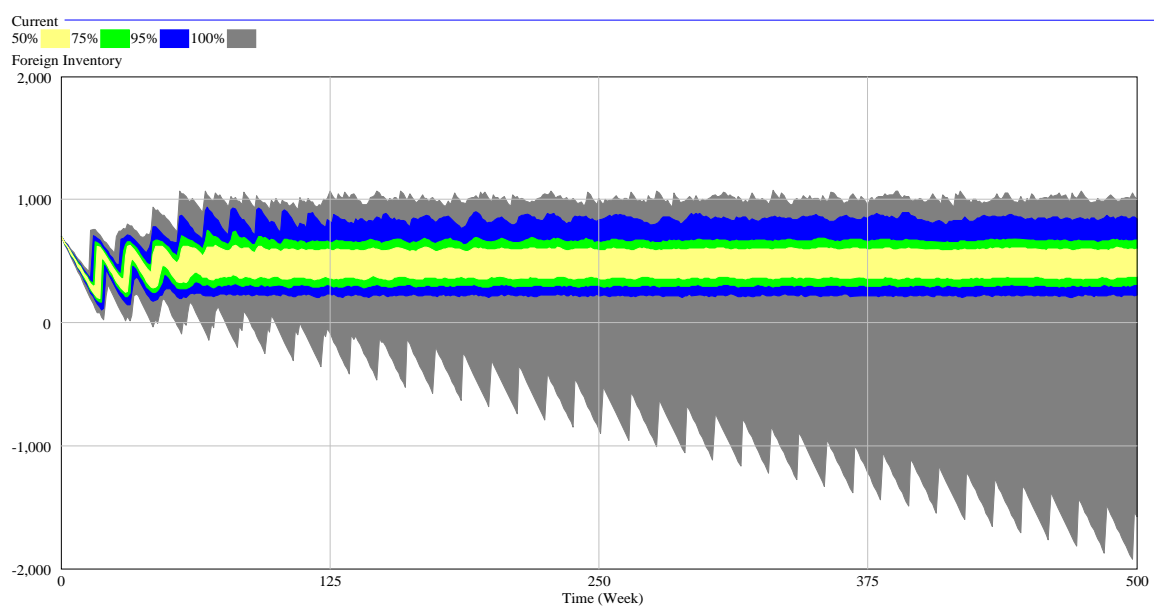

Fig. 5. Inventory amounts in foreign inventory as production is having low variation (uniform distribution 35 to 39 units per week), but average customer demand increases only in very smallscale in uncertainty function (from 26.5 units per week to 29), and transportation process still having uncertainty in delay (same as before).

It can be concluded that the in-transit distribution strategy is workable, but requires low variation in demand, predictable transportation lead-time and low variation of manufacturing output. 


\section{Discussion and conclusions}

The purpose of this research is to investigate the in-transit distribution strategy by determining and analyzing key principles of the strategy and by illustrating its application in practice. This research reveals that the in-transit distribution strategy is about considering goods that are being transported as a mobile inventory and actively dispatching goods to a destination where there is a predicted demand before any customer orders are received. This approach creates a competitive advantage by providing comparatively short lead-times without having to store the goods locally. This in turn gives lower warehousing costs and lower tied-up capital. Accordingly, the in-transit distribution strategy may be a good complement to the traditional distribution strategies for some categories of products, customers, or markets. This is especially true for European manufactures competing in distant market such as Asia and America.

The two involved case companies primarily use the centralized and the decentralized distribution strategy, however, they have started to use the in-transit distribution strategy to a limited extent. Alfa uses the strategy as a complement for large customers in China that have products with a stable demand and high volume, while Beta uses the strategy for two large-volume buying customers in the UK. Both case companies use the in-transit distribution strategy because it generates competitive advantages by offering comparatively short delivery times without having to store large quantities locally, which in turn give lower warehousing costs and lower tied-up capital. For one of the companies the strategy also is used from a sales perspective, which is about the sellers' ability to negotiate on the price at a much later time. This means that they can offer prices that are adjusted to conditions on the markets as close to the delivery date as possible. This is a critical success factor on markets consisting of numerous competitors and where the customers above all focus on cutting prices.

One important issue that needs to be addressed to succeed with the in-transit distribution strategy is where to ship the goods. According to previous research concerning this subject, companies should transport the goods to a destination as close to the predicted demand as possible in order to be able to quickly respond on customer demand as orders arrive [15]. This is partly true for how the case companies operate. Alfa always try to choose a destination port, where they have large customers or local warehouses; this approach is also important to achieve short delivery times to customers when supplying form the intermediate storage. For Beta the choice of destination port is not complicated, they only use the intransit distribution strategy for two customers and transport the goods to the ports closest to these customers. According to the earlier studies, it is also important to consider where to have the intermediate storing if no customer order is received before the goods reaches its destination. Both case companies have made their own solutions for handling the intermediate storing. Alfa deal with it by choosing their own destinations, in this case sea ports, close to local warehouses. If no customer order is received, products are temporarily stored at the local warehouse. Beta has primarily solved this problem by the negotiation of more free of charge days at the sea ports. 
How to plan the flow of goods is another important issue [17]. According to the literature this is about creating the most efficient forecasting as possible. This is somewhat true, how the case companies currently work. Alfa creates a three-year plan and updates it by using a rolling forecast, which is accomplished through each important customer. The forecast is for one year ahead, and is being modified four times per year. Beta creates one forecast per customer, which is for one year ahead and is being modified four times per year. The forecast is, however, only used as a guideline and the actual transported volume is decided by the person placing orders. He or she works together with the sales personnel, and they have continuously communication. The same way of thinking can be found at Alfa as well, but here it is the sales persons that update the rolling forecast. In order for the companies to use the in-transit distribution strategy to an increasing extent it is reasonable to assume that the forecasting needs adjustment. It is important to constantly work with improving the forecasting methods, and the data analyzed, to decrease the uncertainty and by that offer a higher level of service to the customers.

A final important issue that needs to be addressed to succeed with the in-transit distribution strategy is how to deal with demand uncertainty [10]. According to the literature only negative deviations can be dealt with, by the use of having a safety stock, when shipping goods. This is correct for both case companies. To guard against uncertainty in demand both Alfa and Beta are transporting a larger volume than the predicted demand (to maintain a high service level). Nevertheless it is important to make sure that the additional costs for a high service level do not exceed the additional revenues. According to the literature it is moreover important to take into consideration that neither the positive deviations are desirable, since they create a need for intermediate storing. This results in that the safety stock might be creating problems. This is not something that the case companies have to deal with since the fairly easy are able to create intermediate storing of the goods. It may be argued that intermediate storing is perceived as a natural part of the in-transit distribution strategy at both Alfa and Beta, since neither of them work actively with reducing it. This attitude may be explained by the use of the strategy being driven by sales department rather than procurement. Both case companies are experiencing the administration of the in-transit distribution strategy and the associated costs as a key area. For example, the larger part of the administration is manually made in the companies, due to the lack of a sufficient information system. This has caused the companies not to follow up on important statistics. IT systems are important to be able to make the most use of the in-transit distribution strategy and therefore this is something the companies should work actively with improving.

Simulations findings reveal that uncertainty of demand is a key issue of the intransit distribution strategy. The strategy is only applicable in market environments where demand variation is low. In high variation markets either customer satisfaction will be too low or demand for intermediate storing too high. Other requirements to succeed with the in-transit distribution strategy highlighted in the simulation are low variation of manufacturing output and predictable transportation lead-time. Transportation delay between continents, especially from Europe to Asia, is considerable (5-10 weeks) and problematic since the safety 
quantity mechanism is different. In essence, the safety quantity only cover variation in demand since predicted quantity and safety quantity is shipped at the same time.

Interesting aspects for further research would be to continue the study of the involved case companies (particular concerning requirements of predictable transportation lead-time and low variation of manufacturing output), enlarge the study to include more case companies from other businesses, and to extend the simulation model.

\section{References}

[1] M.C. Christopher, H. Peck, and D.R. and Towill: "A taxonomy for selecting global supply chain strategies”, International Journal of Logistics Management, Vol. 17, No. 2, pp. 277287, 2006.

[2] W. Skinner: "The focused factory: New approach to managing manufacturing sees our productivity crisis as the problem of how to compete”, Harvard Business Review, Vol. 52, No. 3, pp.113-121, 1974.

[3] M.C. Christopher, R. Lowson, and H. Peck: "Creating agile supply chains in the fashion industry”, International Journal of Retail and Distribution Management, Vol. 32, No. 8, pp. 367-376, 2004.

[4] M.A. Cohen, and H.L. Lee: "Out of the touch with customer needs? Spare parts and after sales service”, Sloan Management Review, Vol. 31, No. 2, pp. 55-66, 1990.

[5] D.V. Fites: "Make your dealers your partners", Harvard Business Review, Vol. 74, No. 2, pp. 84-95, 1996.

[6] D. Waters: Global Logistics: new directions in supply chain management, Kogan Page, London, UK, 2006.

[7] J.E. Tyworth, and A.Z. Zeng: "Estimating the effects of carrier transit-time performance on logistics costs and service”, Transportation Research Part A, Vol. 32, No. 2, pp. 89-97, 1998.

[8] M.C. Wilson: "The impact of transportation disruptions on supply chain performance", Transportation Research Part E, Vol. 43, No. 4, pp. 295-320, 2007.

[10] G.D. Taylor, D.M. Love, N.W. Weaver, and J. Stone: "Determining inventory service support levels in multi-national companies”, International Journal of Production Economics, Vol. 116, No. 1, pp. 1-11, 2008.

[11] O. Ivanova, and O.-P. Hilmola: "Asian companies and distribution strategies for Russian markets: Case study”, International Journal of Management and Enterprise Development, Vol. 6, No. 3, pp. 376-395, 2009.

[12] J.A. Muckstadt, and L.J. Thomas: "Improving inventory productivity in multilevel distribution systems”, In: Productivity and Efficiency in Distribution Systems, Gautschi, D.A. (ed.), pp. 169-182. Elsevier, New York, 1983.

[13] J. Olhager: Produktionsekonomi, Studentlitteratur, Lund, 2000.

[14] P. Jonsson: Logistics and Supply Chain Management, McGraw-Hill, London, UK, 2008.

[15] J. Mangan, C. Lalwani, and T. Butcher:, Global Logistics and Supply Chain Management, John Wiley \& Sons, London, UK, 2008.

[16] R. Mason, and C. Lalwani: "Mass customized distribution”, International Journal Production Economics, Vol. 114, No. 1, pp. 71-83, 2008.

[17] A. Harrison, and R. van Hoek:, Logistics Management and Strategy, Person Education Limited, Essex, UK, 2008. 